\title{
ROAD CONSTRUCTION LABOR PERFORMANCE CONTROL USING PPC, PCR AND RNC DURING THE PANDEMIC
}

\author{
Jorge R. De La Torre ${ }^{1}$, Luisa J. Taboada ${ }^{2}$, and Pool E. Picoy ${ }^{3}$
}

\begin{abstract}
At the beginning of 2020, the Coronavirus pandemic had various countries negatively affected in the development of their economic activities, as their industries had to interrupt production, hindering their performance and economic development. Before this occurrence, it was known that the evolution of construction labor performance on site was minimum and had high indicators of variability. Due to this, extensive literature reviews have presented Last Planner ${ }^{\circledR}$ System as a methodology to mitigate and improve performance, mostly, in building construction. However, this deficiency presents itself with more frequency in road projects and worsens because of the pandemic.

Having this said, it is important to control labor performance during the sanitary crisis in road projects. Therefore, in this context, the objective of this investigation is to validate the use of Last Planner® System methodology indicators (Percentage of Plan Completed and Percentage of Constraint Removal) as mechanisms of labor control.

The findings evidence a direct relationship between improving indicators of Last Planner® System and a better labor performance while meeting budgeted yields. This in turn has validated the use of Last Planner indicators. Regarding the Reasons for non Completion, the impact of external factors merits and additional investigation due to frequency of occurrence.
\end{abstract}

\section{KEYWORDS}

Last Planner® System, lean construction, variability, performance, labor.

\section{INTRODUCTION}

The start of 2020 has seen a major decline in economic development world wide, the global pandemic has seen many nations interrupt or in some cases halt all of their activities. After a process of disruption and adaptation to the new normal by taking preventative measures against the virus, industries have tried to resume their rhythm of their work. However, achieving previous performance standards has proven to be challenging due to the addition of man hours allocated to comply with health protocols such as temperature control and disinfection. This has increased the amount of work hours

Magister Civil Engineer, Universidad Peruana de Ciencias Aplicadas, Lima, Peru, +51 975355 566, pccijdel@upc.edu.pe, orcid.org/0000-0003-3596-8196

2 Bachelor of School of Civil Engineering, Universidad Peruana de Ciencias Aplicadas, Lima, Peru, +51 994324 260, u201521217@upc.edu.pe, orcid.org/0000-0002-8413-5011

3 Bachelor of School of Civil Engineering, Universidad Peruana de Ciencias Aplicadas, Lima, Peru, +51 922542 234, u201316815@ upc.edu.pe, orcid.org/0000-0003-2372-9083 
in activities that do not provide value to production but are essential. The construction sector nominates such hours as Non-Contributory Time (TNC).

This new reality impacts particularly the construction industry due to the nature of the execution of its activities involving of numerous specialized work force teams which work together to achieve the goals of construction projects (Cost, time, quality) (Sinesilassie et al. 2018). In adition, these past years, the construction industry has been critizicized and compared to other industries due to the reduced evolution of labor performance and the few tools established to control and improve them, which leads to wastes in the processes causing cost overruns and decreased productivity (Bølviken and Koskela, 2016). This was identified by Ballard and Howell in 1992 (Hackett et al. 2019). As shown in Figure 1, while all norwegian industries improve the productivity of their work force, in terms of value added per working hour, there exists a declining trend in labor productivity of on-site construction Activities (Ahmad et al. 2020).

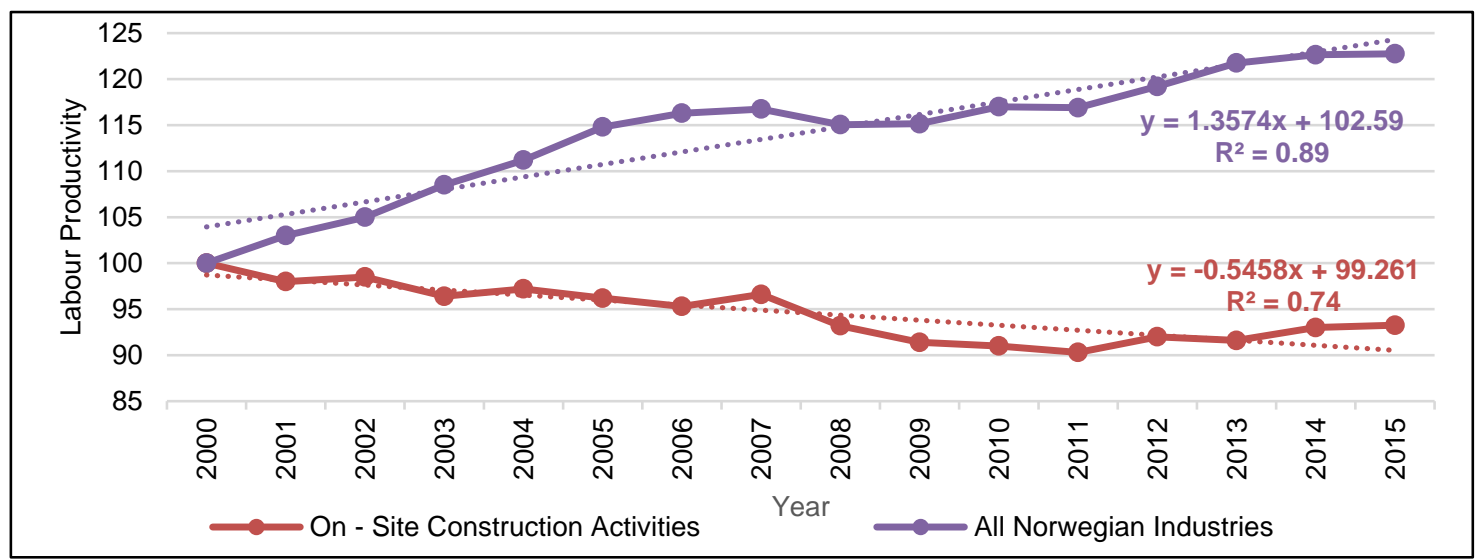

Figure 1: Labour productivity of on-site construction (Figure 15 in Ahmad et al., 2020)

This defect stands out even more in the face of the new normal, due to the increase of TNC and Karunakaran et al. (2019), indicate that it is more frequent in road works due to its longitudinal nature; however, the literature has been limited, for the most part, to address variability through none traditional tools in building construction. According to their research, the causes of variability in road works depend on factors that cause delays in the work flow. These are poor project planning and scheduling, design changes during execution, underground electrical and sanitary networks, material shortages, material and equipment failure, poor communication and interaction, weather, inadequate construction methods, inexperienced contractors and poor site investigation.

According to Radzi et al. (2020), the inefficient performance is found between the most common and significant impacts faced by road construction projects when constraints are not dealt with. Their study proposes that projects that have previously taken care of constraints have imporved scheduale performance by $22 \%$, productivity improvement of $29 \%$ and $21 \%$ less changes during the execution compared to other projects that do not deal with their constraints. i.e. they have less variability. Therefore, this research will use the percentage of constraint removal (PCR), an indicator proposed by Jang and Kim (2007) as a measure for the make-ready process.

Last Planner® System (LPS) is a methodology based off the philosophy of Lean construction (LC) of which's' primary objective is to obtain a reliable workflow through anticipated identification of constraints. According to Ballard and Tommelein (2016), a reliable workflow is achieved by eliminating waste and reducing variability, thus 
improving the work force performance. This reliability can be measured through the percentage of plan completed (PPC) and the performance of resources. In addition, managemental level (work management, plan, task and sequence of work), human resources (labor loyalty, stability of human resources, work force), rework and weather are some of the factors that determine $64.23 \%$ of the reliability of the work flow (Zhang et al. 2017).

On the other hand, according to Li et al. (2019) LC techniques have a positive impact on cooperation between workmen and their supervisors to complete tasks and suggest ways to improve processes, as well as in interactions with customers, which provides a collaborative environment that improves project performance. It is worth mentioning that researchers have experienced time and cost savings due to LC. Liu and Ballard (2008) highlight that in the face of a high PPC trend, the contractor achieved cost improvements of $24 \%$. Similarly, Dallasega et al. (2016), demonstrated a labor savings of $8 \%$ compared to the initial estimate when applying LPS in their case study.

Due to the scarce evolution of labor performance, the few tools that have the capacity to control it and the higher incidence of variability in road projects, this research seeks to demonstrate, within the context of the new normal, the relationship between the control of labor performance of the case study (road project) and the indicators PPC, PCR and reasons for non compliance (RNC), as well as to answer the question: Is it valid to use the indicators PPC, PCR and RNC as a control mechanism of labor performance in road construction within the new normal?

\section{METHOD}

The methodology of this research (Figure 2) was applied to a road work (roads and sidewalks) executed in the city of Lima, capital of Peru, during the last quarter of 2020.

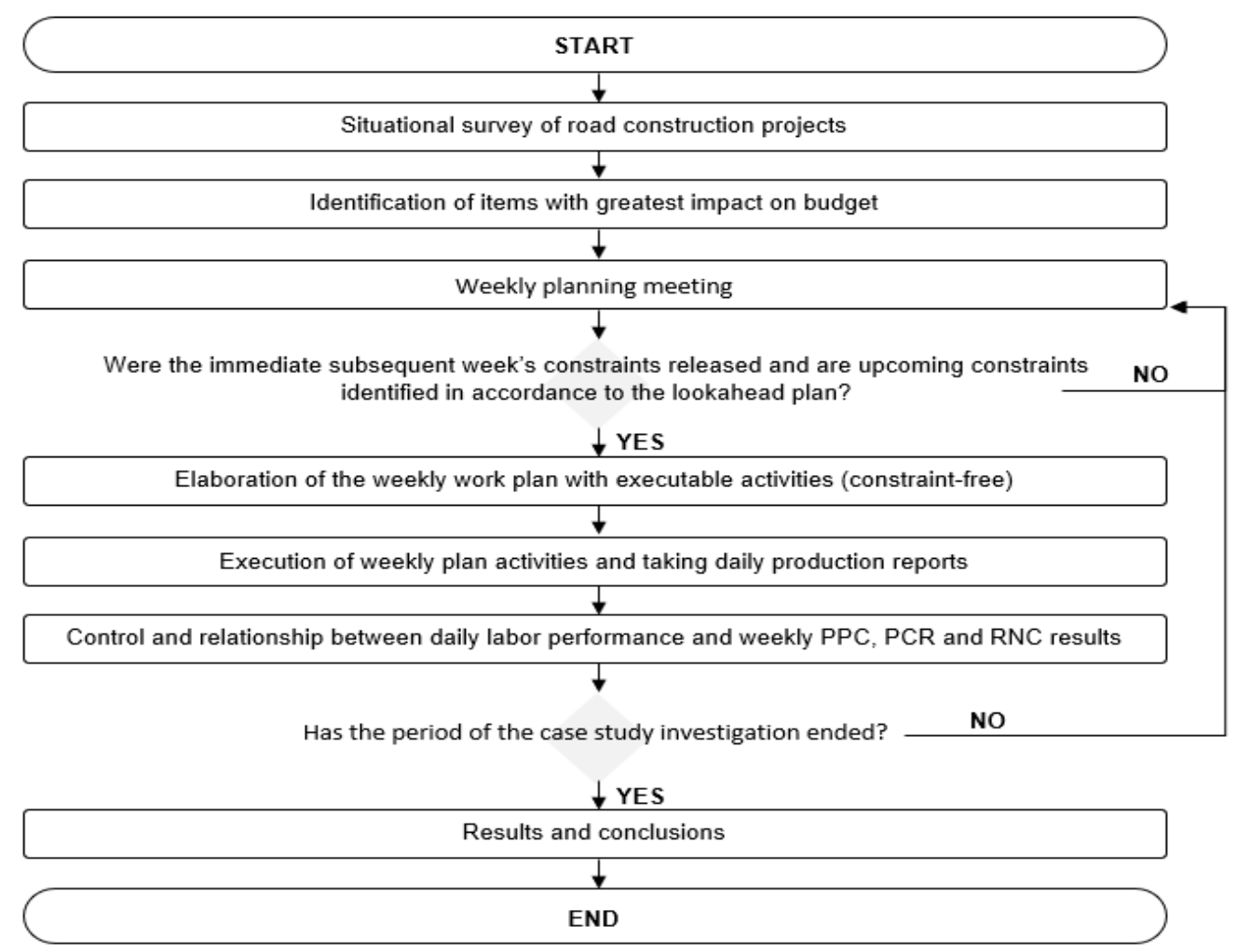

Figure 2: Flowchart of Research Process 
As a first step, a situational survey of road works was made, then the items in execution that had the greatest impact on the budget were identified, with which weekly planning meetings were started for the 6-week period of execution of activities. These meetings were held at the end of each week. In these meetings, activities were updated and constraints were analyzed according to the LookAhead; and activities free of constraints were planned for the following week. Also, the PPC, PCR, RNC indicators and the actual labor performance of the control items of the completed week were evaluated.

Figure 2 represents the methodology used for the control of the labor performance of a road project within the context of the new normal using as a mechanism the PPC and PCR indicators and RNC for decision making oriented to continuous improvement.

\section{Situational Survey of RoAd Construction Projects}

The survey was conducted among 40 professionals from 16 construction companies specializing in road projects during the new normal, from which it was found that $21 \%$ of the respondents, according to their experience, believed that the inadequate composition and size of crews is a factor that negatively impacts labor performance (Figure 3).

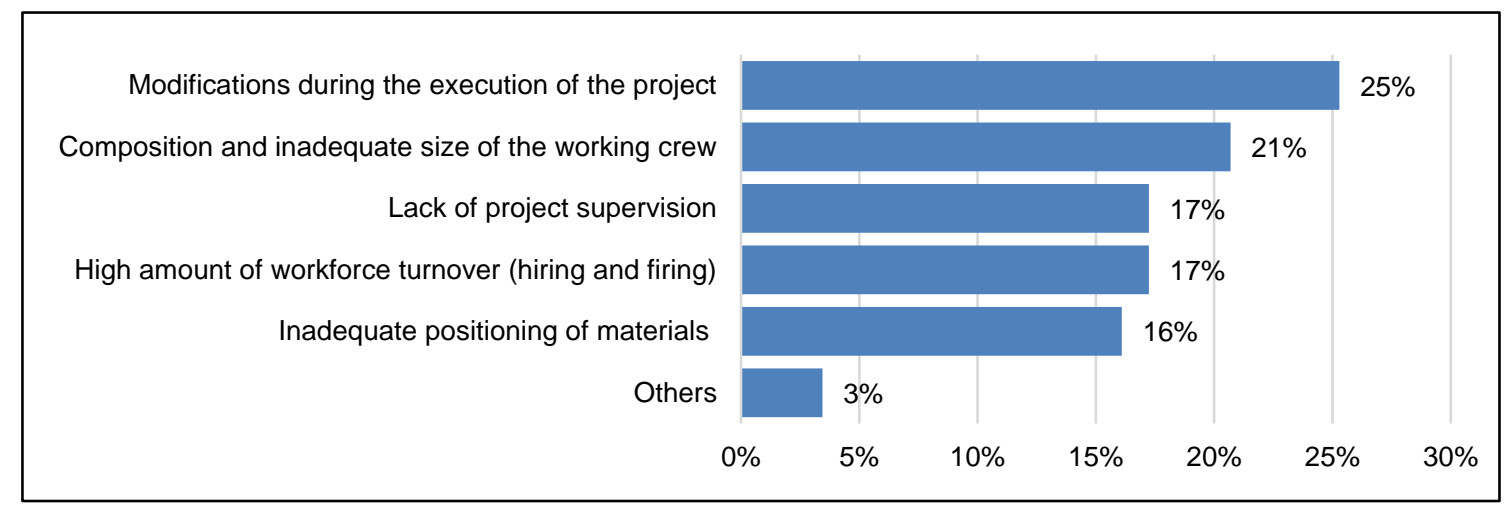

Figure 3: Factor of variability of the labor performance

Likewise, $22 \%$ of the professionals rated Waiting or Downtime as the waste with the greatest impact on labor performance. (Figure 4).

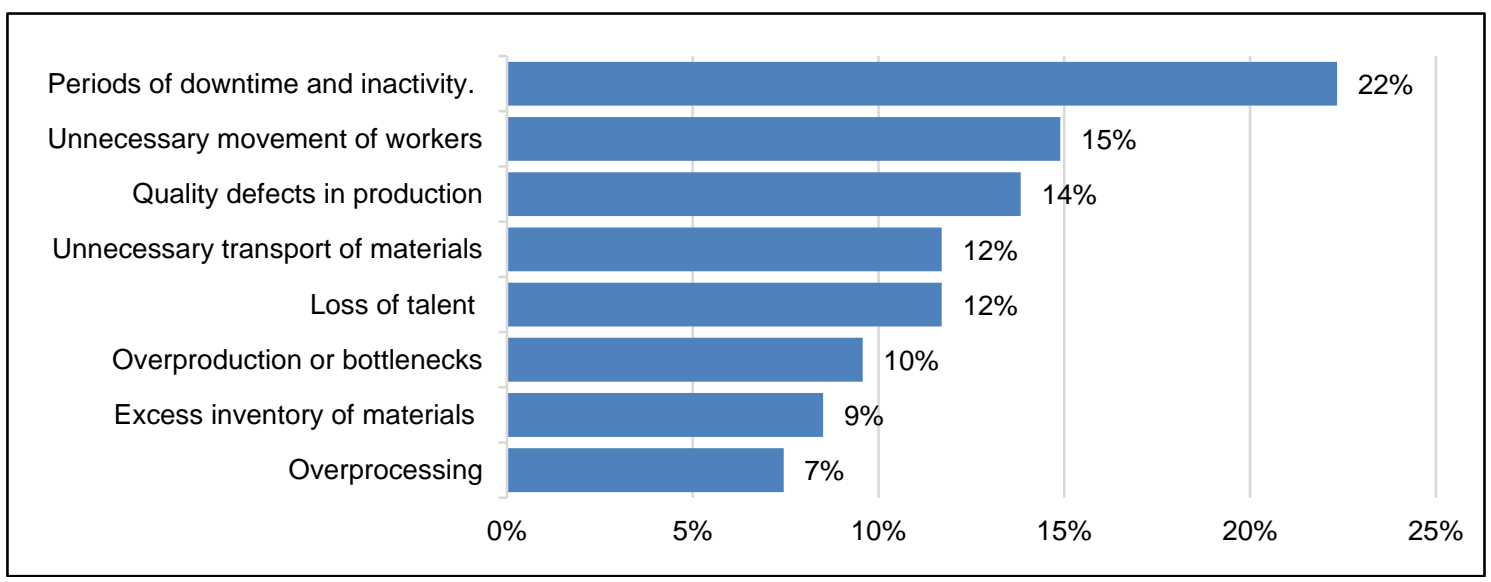

Figure 4: Waste with the greatest impact on labor performance

In addition, Figure 5 shows that, according to specialists, the average Productive Time (TP), i.e., that which the time that workers add direct value to production of executed activities., represents $50.45 \%$ of the activities performed at the construction site. 


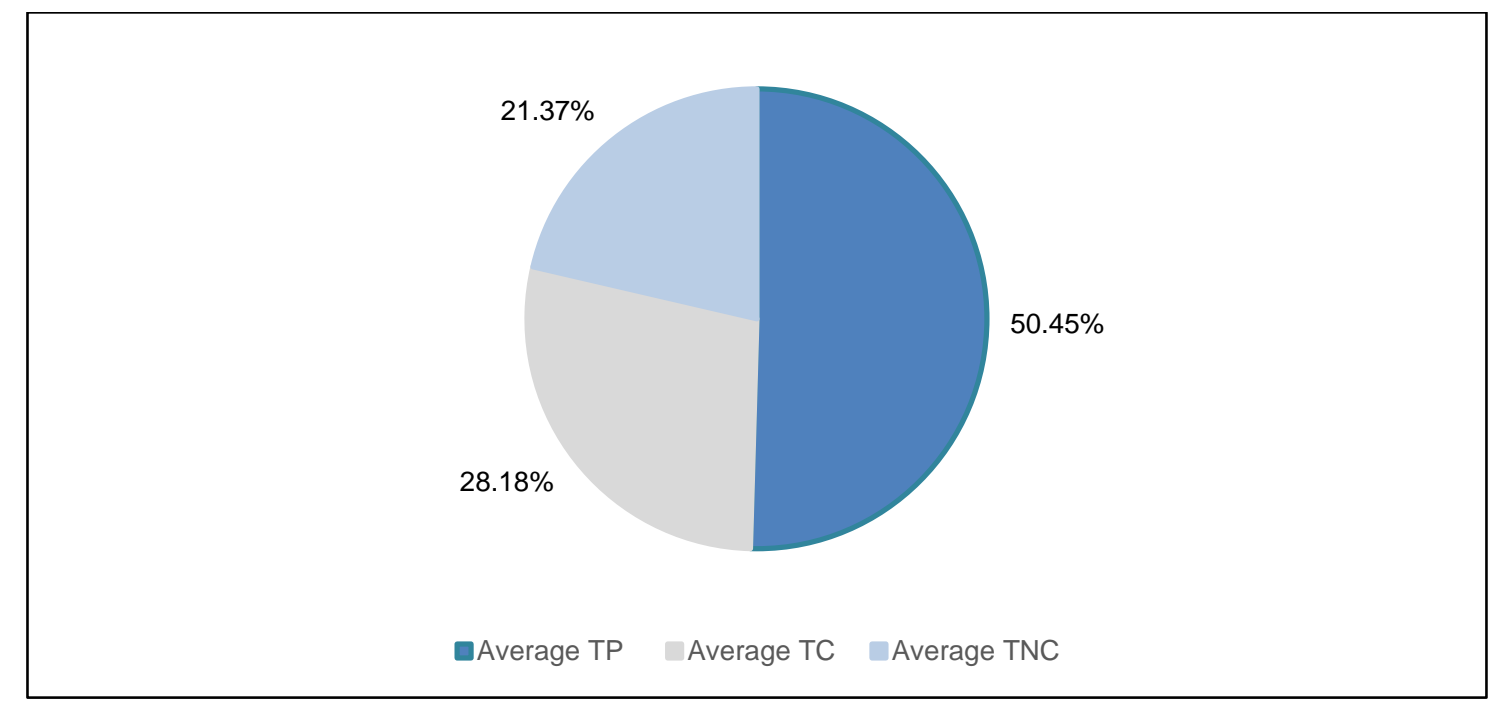

Figure 5: Distribution of types of work times in road projects in the context of new normality

Table 1 presents the causes and consequences of variability provided by road project specialists.

Table 1: Causes and consequences of variability in labor performance. Source: Own elaboration.

\begin{tabular}{|c|c|}
\hline Causes & Consequences \\
\hline Poor planification & Waits, unresolved constraints \\
\hline $\begin{array}{l}\text { Incompatibility between tecnical file and } \\
\text { field reality }\end{array}$ & Rework, cost overuns, and new studies. \\
\hline Natural disasters & Imposibility of work realization due to rain \\
\hline Incompatibility in layouts & Delays and reschedualing of work \\
\hline Indefitions imputed to the client & Time extensions and cost overuns \\
\hline Climate change & Not being able to asphalt or pur pavements \\
\hline $\begin{array}{l}\text { Not having a complete report of } \\
\text { interferences }\end{array}$ & None budgeted extra labor \\
\hline Lead time of resources & Delay \\
\hline $\begin{array}{l}\text { Hiring of unqualified personnel, deficient } \\
\text { programing }\end{array}$ & Low performance \\
\hline Lack of planning and control of production & $\begin{array}{c}\text { Working without clear goals, which implies } \\
\text { greater costs and possibly missing the } \\
\text { deadline. }\end{array}$ \\
\hline Underground interference in urban areas & $\begin{array}{l}\text { Halt of work due to new activities which require } \\
\text { resolution }\end{array}$ \\
\hline
\end{tabular}

These survey results provided a situational overview of road works and guided the PPC and PCR indicators towards a controlled labor performance within the context of the new normal. 


\section{IDENTIFICATION OF ITEMS WITH THE GREATEST INCIDENCE}

Table 2 shows the items that were under execution during the study period. Under the criterion of controlling the labor performance of those that add the most value to the project, the first seven items with the greatest impact on the budget were selected

Table 2: Activities being carried out during the study period

\begin{tabular}{ccc}
\hline $\mathbf{N}^{\circ}$ & Item description & \% impact on budget \\
\hline 1 & Rigid Pavement & $34.76 \%$ \\
2 & Granular Sub-base H=20 cm & $5.66 \%$ \\
3 & Concrete Sidewalks & $4.40 \%$ \\
4 & Pavement painting & $2.99 \%$ \\
5 & Asphalt Contraction Joint Sealing & $1.50 \%$ \\
6 & Excavation to subgrade in Loose Material & $1.20 \%$ \\
7 & Demolition of Flexible Pavement & $1.18 \%$ \\
8 & Installation of guardrails & $1.17 \%$ \\
9 & Painting of guardrail & $1.17 \%$ \\
10 & Ready-mixed concrete for curbs & $0.97 \%$ \\
11 & Excavation and pouring for vertical sign & $0.89 \%$ \\
12 & Ready-mixed concrete for parapets & $0.48 \%$ \\
13 & Cleaning of pavements & $0.36 \%$ \\
14 & Retaining wall & $0.33 \%$ \\
15 & Concrete sewer & $0.21 \%$ \\
16 & Speed bumps & $0.19 \%$ \\
\hline
\end{tabular}

\section{Weekly Planning Meeting}

These meetings were held at the end of each week. In these meetings, the LPS indicators and the yield curves of the control items were evaluated; and the planning for the following week was done. In that sense, the agenda was divided into two parts:

\section{Executed Week Review}

- Percentage of Plan completed (PPC): Indicator to verify compliance with the activities of the Weekly Plan for the week executed (Ballard and Tommelein, 2016).

- Reasons for Non Compliance (RNC): Qualitative indicator through which decisions are made and corrective actions are taken with respect to the activities of the PPC that were not complied with. It also contributes to the continuous improvement of the system (Ballard and Tommelein, 2016).

- Percentage of Constraint Removal (PCR): This indicator verifies compliance with the weekly scheduled release of constraints, allowing the determination of executable tasks (Lagos et al., 2019).

In addition, performance curves were developed in order to establish the relationships between the weekly results of PPC, PCR and labor performance. 
- Labor performance curves: This graph identifies whether the labor resource meets the expected performance (input/output), according to the budget, because if the accumulated performance is higher than the budgeted performance, more man-hours (input) are being used than expected, which translates into cost overruns. This tool is based on data obtained from daily production reports of the control items, which indicate the composition of the work crew (workmen quantity), the amount of production (output) and the hours used for this.

\section{Immediate Post Week Planning}

- Weekly work plan: Detailed work plan for the following week. It is elaborated with activities free of constraints (Executable Tasks).

- Constraint analysis: Performed with information of each constraint that compromises the execution of an activity, identified in the lookahead, in order to determine the time and responsible for releasing it.

- Lookahead Plan: Planning whose time horizon should be equivalent to the time it takes for the most critical constraints to be lifted, so that these are identified and resolved in time. For the case study the time horizon was 3 weeks.

\section{RESULTS}

The results show that the lower the PPC and PCR (Figure 6 and 7), the performance is higher, which translates into inefficient use of resources and cost overruns. This is due to the fact that, in the event of non-compliance with the release of constraints, the workflow is interrupted, which implies greater use of labor resources.

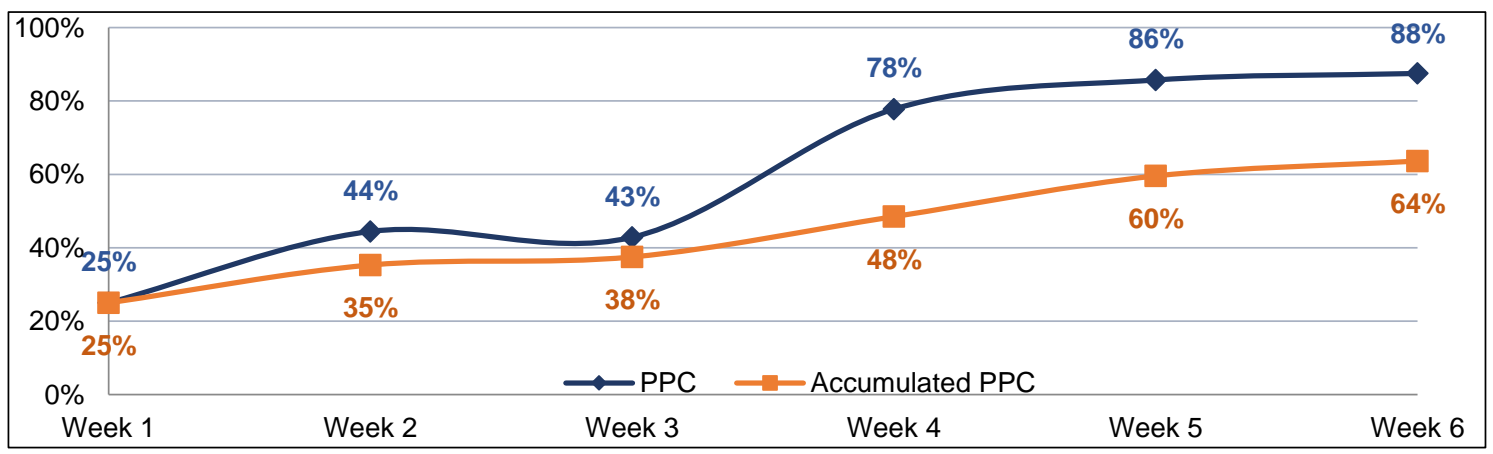

Figure 6: Study Period PPC Graph

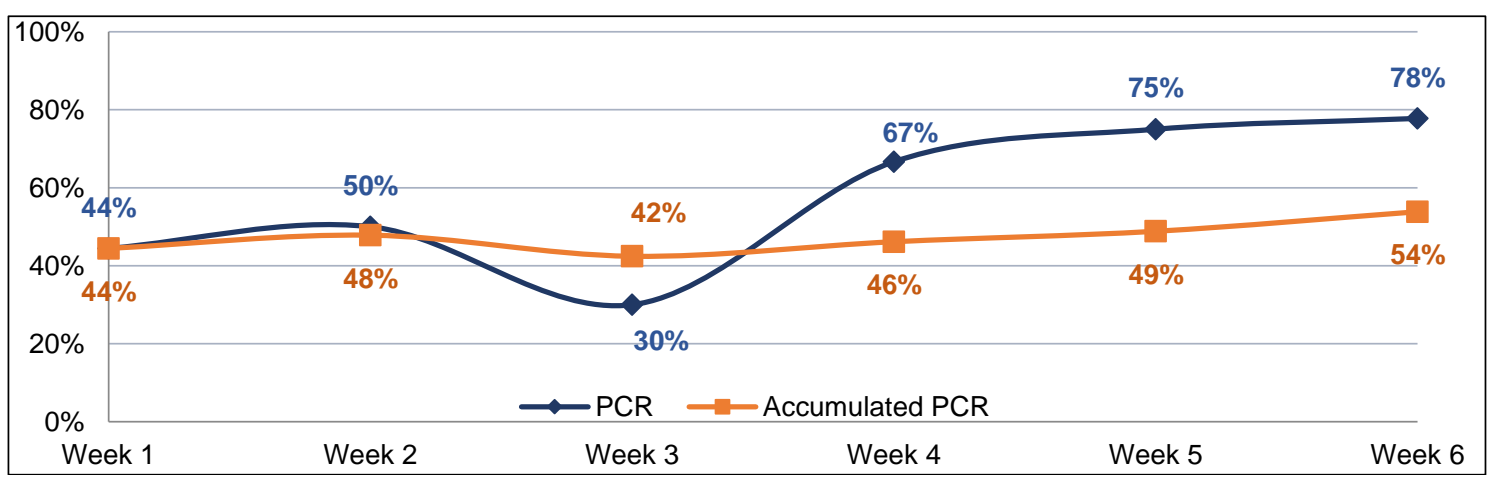

Figure 7: Study Period PCR Graph 
The improvement in performance begins in week 3 (Figure 8), at which point the PPC and PCR tend to rise, which is explained by timely decisions and actions regarding labor and release of constraints.

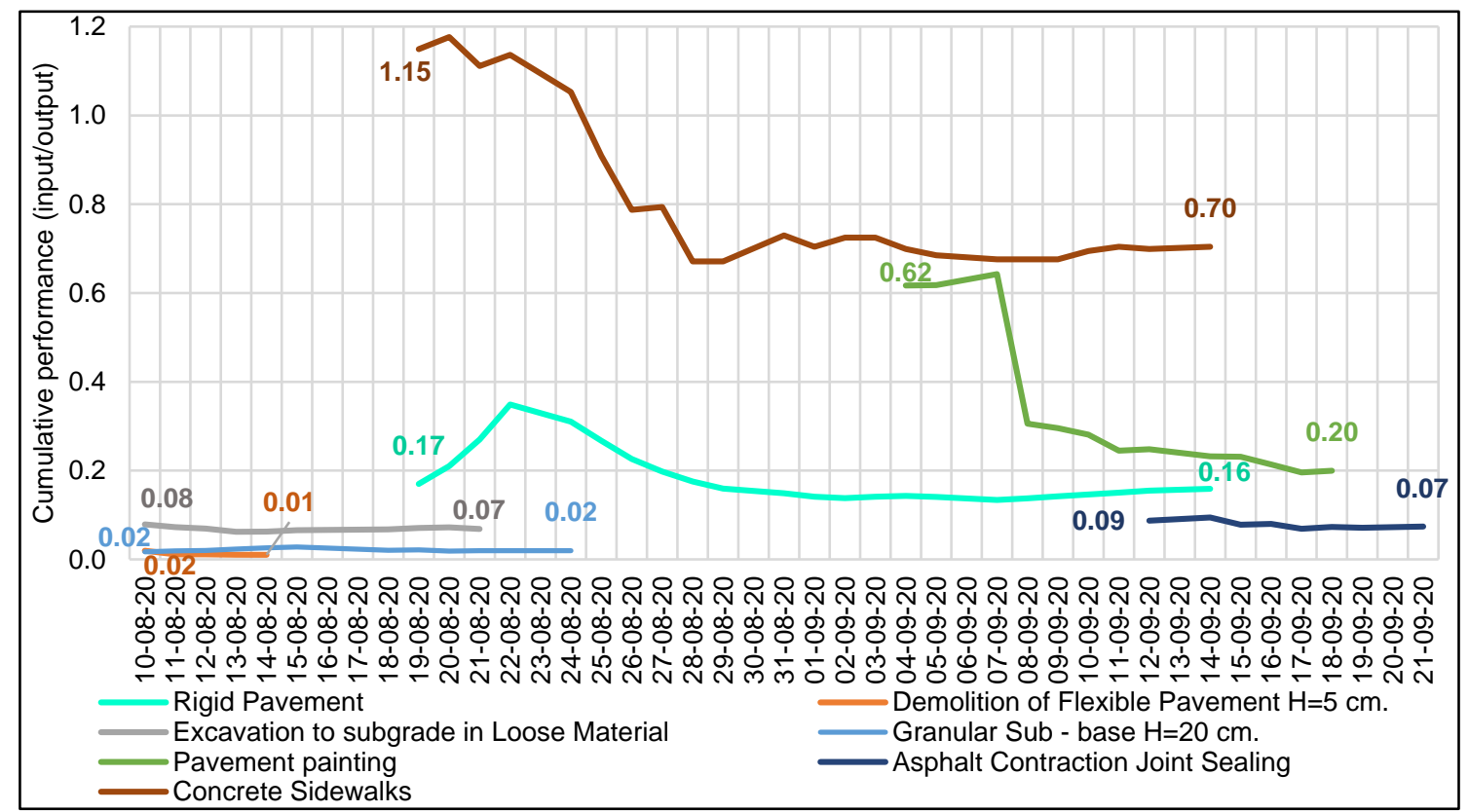

Figure 8: Labor performance curves

It is worth mentioning that some decisions involved more workmen, however, the labor performance was aligned with the budgeted performance of each control item, i.e., the system minimized labor cost overruns, which shows that it was able to control its performance within the current situation, as well as improve production speed, considering 8 hours of daily work (Table 3 ). This last finding is attributed to the weekly analysis of PPC and PCR results and the identification of RNCs to contribute to decisions aimed at continuous improvement of the workflow.

Table 3: Results cumulative labor performance curves

\begin{tabular}{|c|c|c|c|c|c|c|c|}
\hline \multirow[t]{2}{*}{ Item description } & \multirow{2}{*}{$\begin{array}{c}\text { Workmen } \\
\text { Nr. } \\
\text { (a) }\end{array}$} & \multicolumn{3}{|c|}{$\begin{array}{l}\text { Labor Performance } \\
\quad \text { (input/output) }\end{array}$} & \multicolumn{3}{|c|}{ Production speed (output/day) } \\
\hline & & Budgeted & $\begin{array}{c}\text { Start } \\
\text { (b) }\end{array}$ & End (c) & $\begin{array}{l}\text { Start } \\
\frac{1}{b /(a \times 8)}\end{array}$ & $\begin{array}{l}\text { End } \\
\frac{1}{c /(a \times 8)}\end{array}$ & Increase \\
\hline Rigid Pavement $\left(\mathrm{m}^{2}\right)$ & 18 & 0.16 & 0.17 & 0.16 & 848 & 905 & $7 \%$ \\
\hline $\begin{array}{l}\text { Demolition of Flexible } \\
\text { Pavement }\left(\mathrm{m}^{2}\right)\end{array}$ & 6 & 0.19 & 0.02 & 0.01 & 2464 & 4657 & $89 \%$ \\
\hline $\begin{array}{l}\text { Excavation to subgrade in } \\
\text { Loose Material }\left(\mathrm{m}^{3}\right)\end{array}$ & 3 & 0.09 & 0.08 & 0.07 & 305 & 350 & $15 \%$ \\
\hline $\begin{array}{c}\text { Granular Sub-base } \mathrm{H}=20 \mathrm{~cm} \\
\qquad\left(\mathrm{~m}^{2}\right)\end{array}$ & 5 & 0.04 & 0.02 & 0.02 & 2340 & 2037 & $-13 \%$ \\
\hline Pavement painting (m) & 8 & 0.64 & 0.62 & 0.20 & 104 & 320 & $208 \%$ \\
\hline $\begin{array}{l}\text { Asphalt Contraction Joint } \\
\text { Sealing }(m)\end{array}$ & 14 & 1.13 & 0.09 & 0.07 & 1287 & 1512 & $17 \%$ \\
\hline Concrete Sidewalks $\left(\mathrm{m}^{2}\right)$ & 7 & 0.71 & 1.15 & 0.70 & 49 & 80 & $63 \%$ \\
\hline
\end{tabular}


Finally, with respect to the RNCs identified during the current health situation, the most frequent are the external ones with $42 \%$ (Figure 9), since roadworks present factors specific to the type of project that can cause interruptions in the work flow throughout its development, which is why the labor performance is variable. Specifically, the irregularity of vehicular flow and frequent interference with residential access during the new normality was identified, as well as with services such as public lighting poles within the roadway and subway power lines. Therefore, it is recommended that before the start of a road project developed during the current situation, information about these factors be taken, since they represent a constraint and by taking action to release them, a workflow without interruptions and with better labor performance would be achieved.

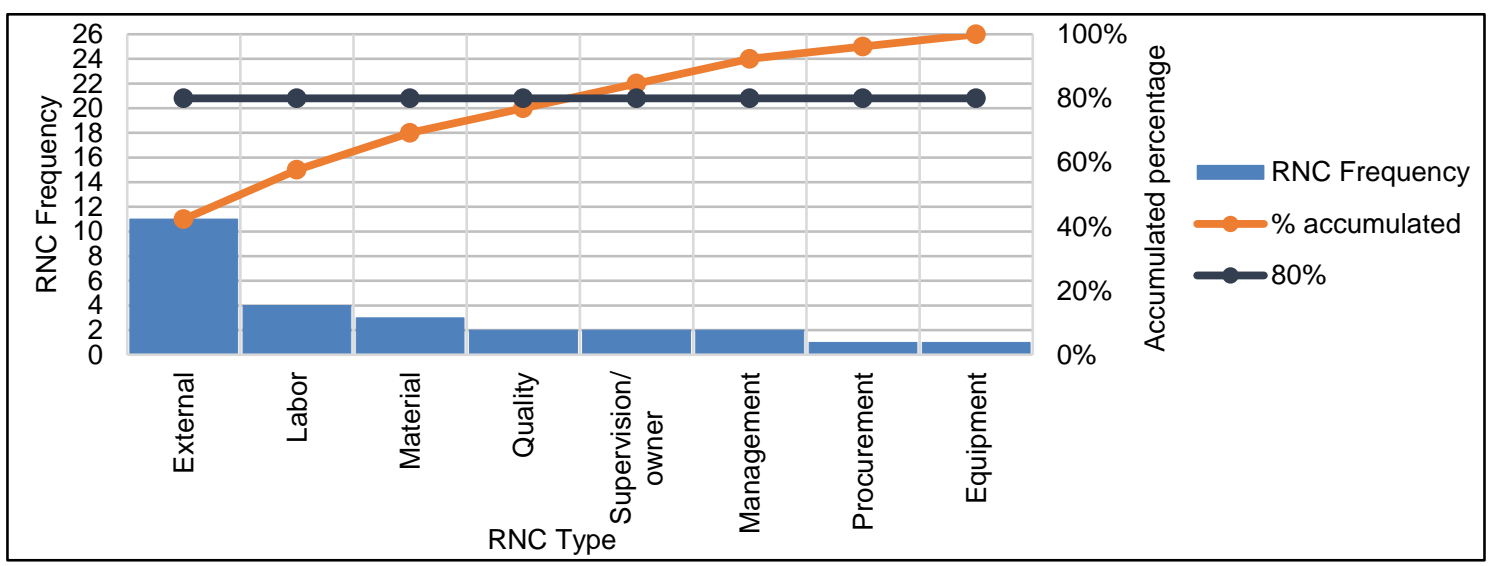

Figure 9: RNC Pareto Chart

\section{CONCLUSIONS}

- It was found that the monitoring of labor performance of road construction projects through the PPC, PCR and RNC indicators generated a positive impact on improving labor performance in road projects developed during the new normal.

- It was verified, according to the Pareto chart, that in the new normality, the greatest source of RNCs are: External, labor, materials and quality with a cumulative percentage of $80 \%$.

- Specific external RNCs during the study period were found to encounter heavy and light traffic problems in the work areas, as well as interference with residential access and domestic public services.

- Better PPC and PCRd were found to be directly related to a labor performance in line with the Budget.

- It was found that when the PCR tends to be higher the PPC is also higher, since the best decisions made during the constraint analysis minimized workflow interruptions by improving labor throughput.

- It was found that low PPC and PCR, translates into and inefficient labor performance which in turn leads to higher cost overruns for the road project.

- A $24 \%$ to $64 \%$ improvement in PPC resulted in up to $67.74 \%$ improvement in the work force performance of the pavement painting control line item.

- This study contributes to existing knowledge and practice, in the context of the pandemic, by validating the methodology for monitoring and optimizing the 
performance of the road construction work force using LPS indicators and collecting RNCs characteristic of the type of work and the health crisis.

\section{REFERENCES}

Ahmad, S. B. S., Mazhar, M. U., Bruland, A., Andersen, B. S., Langlo, J. A., and Torp, O. (2020). Labour productivity statistics: a reality check for the Norwegian construction industry. International Journal of Construction Management, 20(1), 3952. doi.org/10.1080/15623599.2018.1462443.

Ballard, G., and Tommelein, I. (2016). Ballard_Tommelein-2016-Current-ProcessBenchmark-for-the-Last-Planner-System. 1-42.

Bølviken, T., and Koskela, L. (2016). WHY HAS $N$ ' $T$ WASTE REDUCTION CONQUERED CONSTRUCTION ? 2, 3-12.

Dallasega, P., Marcher, C., Marengo, E., Rauch, E., Matt, D. T., and Nutt, W. (2016). A decentralized and pull-based control loop for on-demand delivery in eto construction supply chains. IGLC 2016 - 24th Annual Conference of the International Group for Lean Construction, 33-42.

Hackett, V., Harte, P., and Chendo, J. (2019). The development and use of last planner ${ }^{\circledR}$ system (LPS) guidance. 27th Annual Conference of the International Group for Lean Construction, IGLC 2019, 651-662. doi.org/10.24928/2019/0101.

Jang, J. W., and Kim, Y.-W. (2007). Use of Percent of Constraint Removal to Measure the Make Ready Process. Proceedings IGLC-13, July, 529-538. https://www.iglc.net/papers/details/497.

Karunakaran, S., Malek, M. A., and Ramli, M. Z. (2019). Causes of delay in construction of highway projects: A review. International Journal of Civil Engineering and Technology, 10(2), 2374-2386.

Lagos, C. I., Herrera, R. F., and Alarcón, L. F. (2019). Assessing the Impacts of an IT LPS Support System on Schedule Accomplishment in Construction Projects. Journal of Construction Engineering and Management, 145(10), 04019055. doi.org/10.1061/(ASCE)CO.1943-7862.0001691.

Li, S., Fan, M., and Wu, X. (2019). Lean construction techniques and individual performance. 27th Annual Conference of the International Group for Lean Construction, IGLC 2019, 1469-1477. doi.org/10.24928/2019/0136.

Liu, M., and Ballard, G. (2008). Improving labor productivity through production control. Proceedings of IGLC16: 16th Annual Conference of the International Group for Lean Construction, 657-666.

Radzi, A. R., Rahman, R. A., Doh, S. I., and Esa, M. (2020). Construction readiness parameters for highway projects. IOP Conference Series: Materials Science and Engineering, 712(1). doi.org/10.1088/1757-899X/712/1/012029.

Sinesilassie, E. G., Tabish, S. Z. S., and Jha, K. N. (2018). Critical factors affecting cost performance: a case of Ethiopian public construction projects. International Journal of Construction Management, $18(2), \quad 108-119$. doi.org/10.1080/15623599.2016.1277058.

Zhang, L., Chen, X., and Suo, Y. (2017). Interrelationships among critical factors of work flow reliability in lean construction. Journal of Civil Engineering and Management, 23(5), 621-632. doi.org/10.3846/13923730.2016.1217921. 